\title{
Social Identity's Impact on Service Recovery Evaluations in Alliances
}

\author{
Karin Weber* \\ Assistant Professor \\ School of Hotel and Tourism Management \\ Hong Kong Polytechnic University \\ Hung Hom, Kowloon \\ Hong Kong, SAR, China \\ Tel: + (852) 2766 4031; Fax: + (852) 23629362 \\ Email: hmkweber@polyu.edu.hk \\ Beverley A. Sparks \\ Professor \\ Service Industry Research Centre \\ Griffith University \\ PMB 50, GCMC, 9726, QLD \\ Australia \\ Tel: +(61) 75552 8766; Fax: +(61) 755528507 \\ Email: B.Sparks@gu.edu.au
}

\section{* Corresponding Author}




\title{
Social Identity’s Impact on Service Recovery Evaluations in Alliances
}

\author{
Karin Weber \\ Hong Kong Polytechnic University, China \\ Beverley Sparks \\ Griffith University, Australia
}

The areas of service failure and recovery (SF/R) has recently received considerable research attention (Smith, Bolton \& Wagner, 1999; Sparks \& McCollKennedy, 2001; Tax, Brown \& Chandrashekaran, 1998) due to their critical impacts on customer satisfaction (McCoullough, Berry \& Yadav, 2000), word-of-mouth (Blodgett, Hill \& Tax, 1997) and repeat purchase intentions (Keaveney, 1995). However, thus far research has been limited to investigating the effects of SF/R on customer evaluations where one organization was the sole service provider. Consequently, current research has ignored the impacts of $\mathrm{SF} / \mathrm{R}$ in situations in which two or more service providers are closely linked in the provision of services to the customer by means of an alliance.

Similarly, very few consumer behavior studies to date have looked beyond individual characteristics and their influences on behavior to assess the impact of the social context on consumer responses. Some studies (see for example, Briley \& Wyer, 2002; Grier \& Deshpande, 2001) have focused primarily on the impact of an individual's social identity on advertising responses. However, social identity theory and the related social categorization theory, in particular, have received little attention as potential frameworks to understand why people are concerned about justice in service failure and recovery situations. Formulated by Tajfel and Turner (1979), people's membership in groups forms the basis of social identity theory, with its key premise being that individuals to a varying extent define themselves through the groups to which they belong. A special form of social identification is organizational identification where an individual defines him/herself in terms of membership in a particular organization (Bhattacharya et al. 1995; Dutton et al 1994; Mael \& Ashforth 1992). As such, organizational identification is a construct conceptually substantially different from brand identification, and even more so from brand involvement. According to social identity theory, people need not interact or even feel strong interpersonal ties to perceive themselves as members of a group. Turner (1982) noted that people often socially identify with groups, even when they have no contact with specific members. Impersonal bonds can exist and be derived from a common identification with some symbolic group or social category. Recently, Haslam, Branscombe and Bachmann (2003) examined how social identity affects consumer evaluations in a service failure situation, within a single service provider context. They found that consumers who identify strongly with a service provider (specific firm) appear to be more forgiving to that service provider in a service failure event than consumers who do not identify, especially in terms of repeat purchase intentions. 
Related to social identity is the group value theory (Lind \& Tyler, 1988; Lind 1995), which argues that dignified and respectful treatment is a central consideration for individuals evaluating their standing (status) in a group. Thus, in a service failure event those consumers who strongly identify with a service provider may be especially negative in their evaluations if the firm's service recovery measures signal that $\mathrm{s} / \mathrm{he}$ is not treated with the respect a high standing in the group would warrant. For instance, Frequent Fliers (as a group) would expect to be treated especially well as an indicator of respect that comes with being a loyal consumer.

As part of a larger study, our research sought to investigate the role of social identity by making this characteristic salient (by invoking strong identification with one particular airline, denoted as the home carrier) in consumers' minds when evaluating a service failure. We extend previous research by examining the impact of social identity in an airline alliance setting in which two service organizations are involved in the service provision. Consumers were asked to evaluate the two airlines: a home carrier (an airline a consumer has a preference for and frequently flies with) and its partner airline. We also assess consumers' overall evaluations of the global alliance (such as Oneworld or Star Alliance). Thus, with such a service delivery situation there are three entities that can be evaluated by customers.

Based upon social identity theory and Haslam et al's (2003) work, the following propositions are advanced:

$\mathrm{P}_{1}$. Consumers who identify strongly with the home carrier will be more positive in their evaluation of, and behavior towards, this airline following a service failure than consumers who do not identify with the home carrier.

$\mathrm{P}_{2}$. Consumers who identify strongly with the home carrier will be more positive in their evaluation of, and behavior towards, this airline following a service failure compared to the partner airline and the alliance than consumers who do not identify with the home carrier.

However, due to potential perceived threats to the individual's inclusion and standing in a group an alternative result is possible. Thus, in contrast to $\mathrm{P}_{1}$, and considering justice principles based on the group value model we could expect:

$\mathrm{P}_{1}$ alt. Consumers who identify strongly with the home carrier will be less positive in their evaluation of, and behavior towards, this airline following a service failure than consumers who do not identify with the home carrier. 
Identification with one of the airlines (home carrier) was made salient for respondents through the inclusion of a special script that tapped into the various dimensions of social identification. The service failure/recovery scenario script was developed on the basis of interviews with airline executives and frequent travelers, in addition to reviews of airline surveys on service failures. It depicted a service situation that involved a home carrier, a partner airline and the alliance brand entity on a codeshared flight. In the scenario the home carrier was the airline that caused the failure. The scenario provided detailed information about the relationships between carriers and the alliance. Prior to its administration, the study was pre-tested; subsequent manipulation and credibility checks indicated that the independent variable manipulations were perceived as intended and that the scenario was thought to be believable.

Data were gathered from 255 undergraduate students at a university in the Eastern United States. The sample was equally divided in terms of gender, and respondents' mean age was 21 years $(\mathrm{SD}=1.8)$. About two-thirds of respondents had traveled up to six times in the past year within the United States, with a quarter of respondents reporting the same travel frequency for international travel

Prior to the application of the multivariate analysis of variance (MANOVA) repeated measures technique, preliminary data screening was conducted (Hair, Anderson, Tatham \& Black, 2002), resulting in the deletion of 14 cases to ensure assumptions of MANOVA were met. Thus, a total of 241 cases were available for the main analyses. Next, respondents were classified as either strong or weak identifiers with the home carrier, based on their responses to five individual questions tapping various social identity dimensions. A median split was employed, resulting in 128 strong identifiers and 113 weak identifiers. Identification (measured) and organizational entity (home carrier, partner airline and alliance) represented the independent variables while overall satisfaction and repeat purchase intention measures were the two dependent variables (both measured on a seven-point scale). We also measured perception of responsibility for the service failure on a ten-point scale, where higher scores indicated greater attributions of responsibility.

A 2 (social identification) x 3 (entity) mixed model MANOVA was computed with two dependent variables (satisfaction and repeat purchase). A significant overall multivariate between-subject main effect was found for social identification $(F[2,234]=$ 3.398, $p=.035$ ). Univariate results showed a significant effect on overall satisfaction $(\mathrm{F}=5.589, \mathrm{p}=.019)$. The pattern of this effect demonstrated that respondents who identified more highly with the home carrier tended to report higher levels of dissatisfaction across all entities (home, partner and alliance) than did the low identifiers. There was no significant effect of social identity for repeat purchase.

In addition to the between-subject effect for social identification, a within-subject main effect was detected for entity $(\mathrm{F}[4,232]=8.981, \mathrm{p}=.000)$. Univariate results revealed a significant effect on repeat purchase intentions $(\mathrm{F}=12.471, \mathrm{p}=.000)$, with respondents appearing to be more willing to fly with their home carrier again following 
the service failure than with the partner airline and in particular, the alliance ( $M=4.34$; 4.09, and 3.80 respectively). There was no significant effect of entity for satisfaction.

The findings did not support $\mathrm{P}_{1}$ or $\mathrm{P}_{2}$. Partial support is provided for $\mathrm{P}_{1}$ alt in that there was a significant main effect for social identity on the level of satisfaction reported (but not for repeat purchase intentions), with respondents in the high SI group showing more dissatisfaction, but it was not just confined to the home carrier. It seems that those customers who felt high identification with the firm may also have more at stake when service delivery fails because not only is there a service problem but the customers' sense of self worth may be compromised. Furthermore, as Lind and Tyler (1988) assert the perceptions conveyed as a result of the service failure event may threaten the consumer's inclusion and standing in the group. This in part helps to shed light on why people in the high social identification group felt a greater sense of dissatisfaction than those in the low social identification group; we suspect they felt their rights and privileges as fully fledged member of a frequent flier program were ignored.

The evaluations of each entity showed that the alliance was held in low regard, with respondents indicating that they did not want to associate with it in future. The alliance was attributed the greatest amount of responsibility, even though the home carrier caused the problem. The alliance was depicted in the scenario as promoting 'seamless' travel and apparently, when this message was contradicted through a service failure, respondents were ready to assign responsibility and not use the alliance again.

In conclusion, the issues investigated here are more far-reaching than the alliance context - in effect, we examined the impact of service failures by one service provider on another closely linked service provider. While we focused on alliances where there is a close relationship between service providers, the results are also of interest to service providers in (more loosely integrated) service networks (e.g., Smith \& Tax, 2005). In an airline context, strategic alliances may be less relevant in domestic travel markets. However, the practice of code-sharing - an integral component of alliances - is commonplace in both international and domestic markets. Thus, the results of our study are of interest and relevant to a wide range of circumstances. While this preliminary study sought to investigate causal relationships within an experimental design, subsequent research could investigate whether the findings of this study extend to a more representative sample, i.e., international frequent flyers. This would overcome a limitation of the present research, namely the use of a student sample. Including nationalism or brand attitudes as covariates may also help further explain the complexity of evaluations within multiple service provider contexts. 


\title{
Research Note
}

\author{
Karin Weber \\ Assistant Professor \\ School of Hotel and Tourism Management \\ Hong Kong Polytechnic University \\ Hung Hom, Kowloon \\ Hong Kong, SAR, China \\ Tel: + (852) 2766 4031; Fax: + (852) 23629362 \\ Email: hmkweber@polyu.edu.hk
}

\section{References}

Bhattacharya, C.B., H. Rao, and M. A. Glynn

1995. Understanding the Bond of Identification: An Investigation of its Correlates

Deleted:

I

ก

Among Art Museum Members. Journal of Marketing 59 (October), 46-57.

Blodgett, J.G., D.J. Hill, and S. S. Tax.

1997. The effects of distributive, procedural and interactional justice on service complaint behavior. Journal of Retailing 73 (2):185-210.

Briley, D. A, and R. S. Wyer Jr.

2002. The effect of group membership salience on the avoidance of negative outcomes: Implications for social and consumer decisions. Journal of Consumer Research 29 (3):400-415.

Dutton, Jane M. and C.V. Harquail 1994.Organizational Images and Member Identification. Administrative Science Quarterly, 39 (34). 239-63.

Grier, S. A., and R. Deshpande.

2001. Social dimensions of consumer distinctiveness: The influence of social status on group identity and advertising persuasion. Journal of Marketing Research 28 ((May)):216-224.

Hair, J.F. Jr., R.E. Anderson, R.L. Tatham, and W.C. Black. 2002. Multivariate data analysis. 6th ed. Upper Saddle River, NJ: Prentice Hall.

Haslam, S. A., N. R Branscombe, and S. Bachmann.

2003. Why consumers rebel: Social identity and the etiology of adverse reactions to service failure. In Social identity at work: developing theory for organizational practice, edited by S. A. Haslam, M. J. Platov and N. Ellemers. New York: Psychology Press.

Keaveney, S.M. 1995. Customer switching behavior in service industries: An exploratory study. Journal of Marketing 59 (April):71-82.

Lind, E.A., and T.R Tyler. 1988. The social psychology of procedural justice. New York: Plenum.

Mael, Fred and B.E. Ashforth 1992. Alumni and Their Alma Mater: A Partial Test of the Reformulated Model of Organizational Identification. Journal of Organizational Behavior 13, 103-23. 
McCollough, M.A., L.L. Berry, and M.S. Yadav.

2000. An empirical investigation of customer satisfaction after service failure and recovery. Journal of Service Research 3 (2):121-137.

Smith, A. K., R. N. Bolton, and J. Wagner.

1999. A model of customer satisfaction with service encounters involving failure and recovery. Journal of Marketing Research 36 (3):356-372.

Smith, A. K, and S.S. Tax

2005. A pound of flesh, but from whom? Assessing failure and recovery in a service network. Presentation at the 2005 AMA Servsig Conference. Singapore, June 2005.

Sparks, B.A., and J.R. McColl-Kennedy.

2001. Justice strategy options for increased customer satisfaction in a services recovery setting. Journal of Business Research 54 (3):209-218.

Tajfel, H., and J.C. Turner. 1979. An integrative theory of intergroup conflict. In The social psychology of intergroup relations, edited by W. G. Austin and S. Worchel. Monterey, CA: Brooks/Cole.

Tax, S. S., S. W. Brown, and M.Chandrashekaran. 1998. Customer evaluations of service complaint experiences: Implications for relationship marketing. Journal of Marketing 62 (April):60-76.

Turner, J.C.

1982. Towards a cognitive redefinition of the social group. In H. Tajfel (Ed.)

Social Identity and Intergroup Relations (pp. 15-40).Cambridge, UK: Cambridge University Press.

Tyler, T.R, and E.A. Lind.

1992. A relational model of authority in groups. In Advances in experimental

social psychology, edited by M. P. Zanna. San Diego, CA: Academic Press. 